\title{
Reinforced Concrete Bridge Deck Model Considering Delayed Exposure to Chlorides
}

\author{
Petr Konečný ${ }^{1}$, Petr Lehner ${ }^{1}$, David Pustka ${ }^{2 *}$ \\ ${ }^{1}$ Department of Structural Mechanics, \\ Faculty of Civil Engineering, \\ VŠB - Technical University of Ostrava, \\ 70833 Ostrava-Poruba, L. Podéště 1875, Czech Republic \\ 2 Department of Structures, \\ Faculty of Civil Engineering, \\ VŠB - Technical University of Ostrava, \\ 70833 Ostrava-Poruba, L. Podéště 1875, Czech Republic \\ * Corresponding author, e-mail: david.pustka@vsb.cz
}

Received: 23 January 2019, Accepted: 30 May 2019, Published online: 05 July 2019

\begin{abstract}
The paper is focused on the model of the effect of delayed chloride exposure on the chloride induced corrosion initiation on ideal reinforced concrete bridge. The Finite Element-based numerical model is applied. The effect of concrete quality is expressed in the form of time dependent diffusion coefficient in order to evaluate the effect of concrete type as well as the effect of aging. The influence of extended chloride exposure on the corrosion initiation is introduced.
\end{abstract}

Keywords

concrete, bridge deck, chlorides, corrosion, finite element analysis

\section{Introduction}

The durability of the public infrastructure is of great interest nowadays. Many structures require early repairs, reconstructions or replacement as a result of durability related issues such as corrosion of steel in case of reinforced concrete bridges.

The development of more durable concrete structures goes hand in hand with the advanced design as well as advanced modelling. The models for the corrosion related durability estimation are under long lasting intensive development (see e.g. [1-11]. There are also codification attempts $[12,13]$ even though reliable prediction is not still achieved. However, the models are suitable for comparative and parametric studies that are investigating influence of particular issues or technological solutions with respect to extension of the reinforced construction lifespan.

For such comparative studies may be used simplified 1D or 2D model such as [3]. This particular model is capable of corrosion initiation estimation of ideal bridge deck as well as bridge deck with cracking or waterproof membrane considering the time-dependent effect of concrete maturity. The above mentioned model [3] describes the resistance against chloride penetration via diffusion coefficient and the time-dependent feature is described by the aging factor $[14,15]$. The lower the diffusion coefficient, the better the resistance against chloride ingress. The higher the aging factor, the higher is the rate of the concrete maturing improving the resistance against chloride penetration and decreasing diffusion coefficient.

One of the aspects that might influence the extension of corrosion initiation in case of reinforced concrete bridge deck exposed to chlorides is the delay between the construction and chloride exposure. It means, how long will be a bridge deck without deicing after construction.

Information about the effect of the influence of deicing on the extension of the life span of bridge or its part maybe useful for highway agencies. However, it is hard to imagine that new construction would be waiting one year for commissioning because of the traffic delays and expenses related with traffic jams and trade efficiency. However, if for example, one year of delay of deicing on the concrete element may extend the durability by e.g. ten years than it would be really worth consideration to find a way 
how to let the concrete mature longer. For example, in case of the precast concrete elements, one can imagine that at earlier stage of the construction process, the concrete elements are fabricated and let mature either on site or in dedicated storage place in order to improve the concrete resistance against chloride ingress before the first deicers application.

Answer to the effect of delay in deicing on the bridge deck chloride ingress related durability, might give the numerical models. For such evaluation of concrete longterm behavior, the description of concrete time-dependent behavior is necessary. The laboratory evaluation of concrete diffusion coefficient as well as aging factors for 33 selected concrete binary and ternary mixtures is available [16]. The study contained data about indirect measurements of concrete ability to resist chloride ingress via electrical conductivity and resistivity [17]. The ability of concrete to resist chloride ingress may be computed next [18] as shown for the studied mixtures in [19]. Moreover, for the ideal bridge deck, the effect of chloride penetration into various High Performance Concrete mixtures (HPC) has been shown in [11].

Sample analysis of the effect of chloride ingress for ideal bridge decks without cracks from two mixtures has been prepared in [20]. However, the effect of the rate of concrete maturing combined with chloride build-up models is worth further evaluation with respect to specific combinations of the diffusion coefficient model. Mainly the interaction of the short-time and long-time diffusion resistance properties is of interest with respect to the delayed deicers application.

The article is focused on the utilization of the numerical solution of reinforced concrete corrosion initiation that is able to model delayed exposure of chlorides on reinforced concrete bridge deck. There are selected 6 mixtures from [16] that corresponds to potential concrete types with considering also effect of maturing/aging.

The quality of concrete with respect to delay of chlorides is evaluated in order to address the question if the delay in chloride ingress significant issue is both from practical as well as numerical standpoint. Especially, the significance of early age diffusion coefficient and aging factor is studied. It is expected that the concrete with high aging factor might be influenced by the delayed application of chlorides more significantly. On the other hand, concrete with low aging factor will not be affected by the delay of salt application as much.
Example of the steel corrosion initiation assessment using the chloride ingress model of the bridge decks with crack effect was considered in [19] without the aging effect and with the consideration of aging effect $[14,15]$ on the improvement of concrete resistance against chlorides over the time was presented in [3]. Both works lack the consideration of the effect of delay in chloride application.

It is worth mentioning that the results of the model have limitations, see e.g. [21]. Numerical models are evaluated based on the laboratory conditions and the real chloride penetration depends on the actual season, temperature concrete humidity, level of mechanical damage [12, 22-24]. The rate of penetration is influenced by surface concentration that changes over the year $[25,26]$. The free soluble chlorides might transform into bound chlorides when the concentration of the pore solution is too high during the deicing season and dissolve back into solution when the concentration of pore solution is lower during warmer rainy season. This complex phenomenon is not fully exploited yet. Thus, the models are suitable for the evaluation of different scenarios with similar boundary conditions. Such example is studied in the paper, that aims to study the effect of concrete mixtures and the effect of the delay of deicing procedures on the corrosion initiation of steel reinforcement embedded in concrete. One needs to take into account that the answer is rather qualitative than quantitative. In other words, we can find what scenario performs better comparing to others rather than insisting on the particular age when the corrosion is initiated.

\section{Chloride ingress related corrosion initiation model}

The Finite element model [3] based on the second Fick's Law of diffusion is used in order to describe the transport of chloride ions through a reinforced concrete bridge deck. The model estimates the concentration of chlorides at the reinforcement level. The model has simplified capabilities of handling the concrete crack effect, epoxide coating protection of the reinforcement, as well as description of the damage to the waterproof insulation that is in between a structural concrete and an asphalt surface layer.

Model allows for chloride ingress modeling and corrosion initiation analysis. The bridge deck durability evaluation strategy is based on the works [5] and [6], enriched by a special description of the effect of cracks in the directly exposed bridge deck [3] even though the crack effect will not be investigated in presented paper. The available model is also supplemented with the effects of the aging of concrete via time varied diffusion coefficients [11]. 
Thus, change of the diffusion coefficient due to the concrete aging is respected as formulated e.g. in [15] and [27]. Therefore, the first step is a calculation of the time dependent diffusion coefficient:

$D_{\mathrm{c}}(t)=D_{\mathrm{c}, \mathrm{ref}} \cdot\left(\frac{t_{\mathrm{ref}}}{t}\right)^{m}$,

where is $D_{\text {c,ref }}$ nominal diffusion coefficient for a selected age $\left[\mathrm{m}^{2} / \mathrm{s}\right]$. Concrete age is $t$ [yrs] while $t_{\text {ref }}$ [yrs] is reference period of measurement. Aging factor is $m$ [-].

Since the effect of delayed chloride exposure is of interest herein, the surface chloride concentration time dependent change is introduced into the model [3]. The surface concentration $C_{0}$ may be applied as stepped value after a delay in chloride exposure or with gradual build-up (similarly to Life 365 [2]). See graphical description at Fig. 1.

Three-node finite elements are used. The model depth is $0.2 \mathrm{~m}$ and width is $0.01 \mathrm{~m}$, thus modeling $1 \mathrm{D}$ problem. The triangular elements are applied in regular rectangular grid of dimensions 10 by $10 \mathrm{~mm}$. The time step of the time related analysis (transient analysis) is controlled automatically on the basis of the size of the element and the diffusion coefficient.

The output of the model is the concentration of chlorides $C_{\mathrm{xy}, \mathrm{t}}$ at the reinforcement level. Through a comparison of the chloride threshold $C_{\mathrm{th}}$ with the actual concentration at a given time, the presence of corrosion is evaluated. The actual concentration is compared with corrosion threshold $C_{\text {th }}$. Thus, the durability of bridge decks is describable by the time dependent reliability function $R F_{\mathrm{t}}$ that is:

$R F_{\mathrm{t}}=C_{\mathrm{th}}-C_{\mathrm{xy}, \mathrm{t}}$
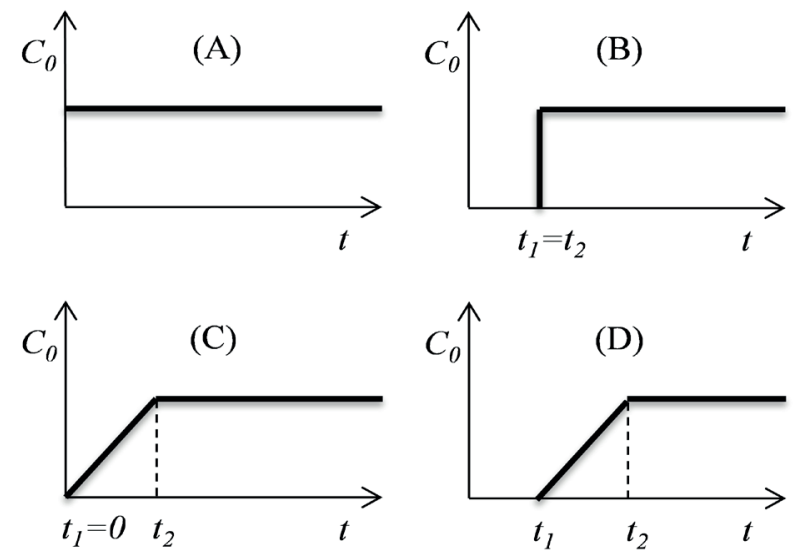

Fig. 1 Time dependent surface chloride concentration $C_{0}$ : (A) constant value, (B) delay and step to constant value, (C) linear chloride buildup to constant value, and (D) delay and linear chloride build-up to constant value
Durability can be related to the initiation of corrosion which corresponds to relationship (2) or the decrease in the area of reinforcement or the occurrence of cracks caused by corrosion due to chlorides.

The period to the start of corrosion $t_{\mathrm{i}}$ can be determined from the reliability function $R F_{\mathrm{t}}$ when chloride action and chloride threshold are in balance.

\section{Sample numerical analyses}

\subsection{Input parameters}

To show the capabilities of introduced feature, the solution for two types of concrete and stepped increase of chloride concentration from zero to actual surface concentration $C_{0}$ denoted above as (B) is shown next.

There are considered two concrete mix design variants. In the model with ordinary concrete (alternative 100TII-V), the referential diffusion coefficient $D_{\mathrm{c}, 28}$ within 28 days of concreting is considered as $5.59 \times 10^{-12}\left[\mathrm{~m}^{2} / \mathrm{s}\right]$ and $m$ is 0.284 , which corresponds to the average value of the 100TII mix [16]. The HPC variant, denoted as $50 \mathrm{TII}-\mathrm{V} / 40 \mathrm{G} 120 \mathrm{~S} / 10 \mathrm{M}[16]$, has $D_{\mathrm{c}, 28}=2.11 \times 10^{-12}\left[\mathrm{~m}^{2} / \mathrm{s}\right]$ and $m$ is 0.573 .

The mixtures are identified by the mass percentage of cement replacement, e.g. the mixture 50TIIV/40G120S/10M consists of 50 percent of Portland cement type TII-V, 40 percent of ground granulated blast furnace slag of grade 120 , and 10 percent replacement by metakaolin.

The value of the concentration at which the initiation of corrosion $C_{\text {th }}$ occurs is 0.18 [wgt \%/cem]. The clear cover of concrete reinforcement above the upper layer of reinforcement is $0.05 \mathrm{~m}$.

The initial concentration on the concrete surface $C_{0}$ is chosen as 1.8 [wgt \%/cem] of soluble chloride ions. The corrosion initiation time is computed with constant $C_{0}$ first. The computation is repeated again with the delay in chloride exposure. The concentration is immediately after the delay modeled as full value $C_{0}$. The exposure delay $t_{1}$ is ranging from one to five years.

\subsection{Results and discussion}

For ordinary concrete mix and no chloride exposure delay, the time to onset of corrosion is computed as 6.4 years and for HPC mixture is this theoretical time 399.5 years, respectively. If the application of chlorides is delayed by 5 years than ordinary concrete mix resist 14 years while HPC mixture resist 525.3 years. The difference between OPC seems to be dramatic but it needs to be noted that this 
is the theoretical result based on considered assumptions and simplifications such as fully saturated ideal 1D bridge deck without cracking and the way the surface concentration of chlorides is applied.

The output from the simulation of corrosion initiation time is shown on the Fig. 2. The result that compares relative increase of durability due to the delay in chloride exposure is given in Fig. 3. Here, the time to onset of corrosion obtained without the exposure delay is considered as baseline.

The increase in time to onset of corrosion for ordinary concrete mix is 2.2 times more comparing no delay and five years delay, for HPC mixture is this increase 1.31 times, respectively.

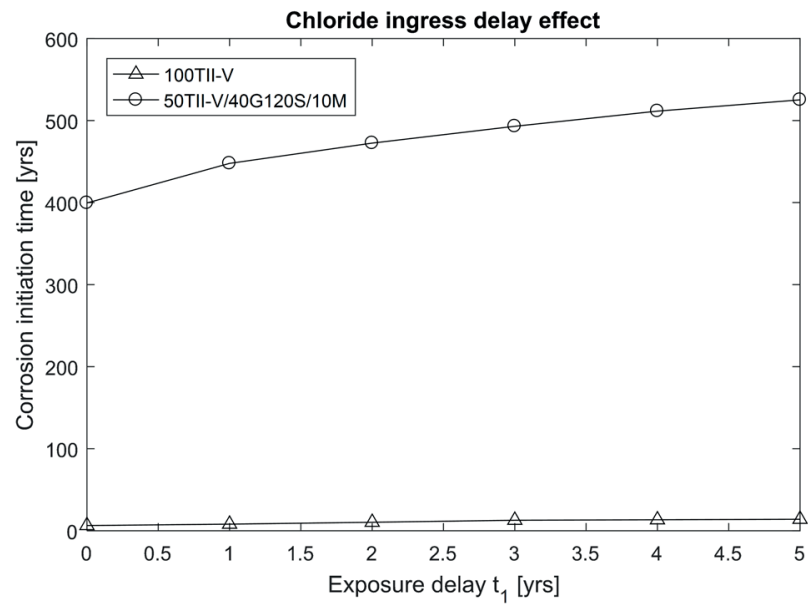

Fig. 2 The effect of delayed exposure of chlorides on increase of corrosion initiation time in case of ideal bridge deck without cracks for two selected concrete mixtures (ordinary concrete mix 100TII-V and high performance concrete mixture 50TII-V/40G120S/10M) [20]

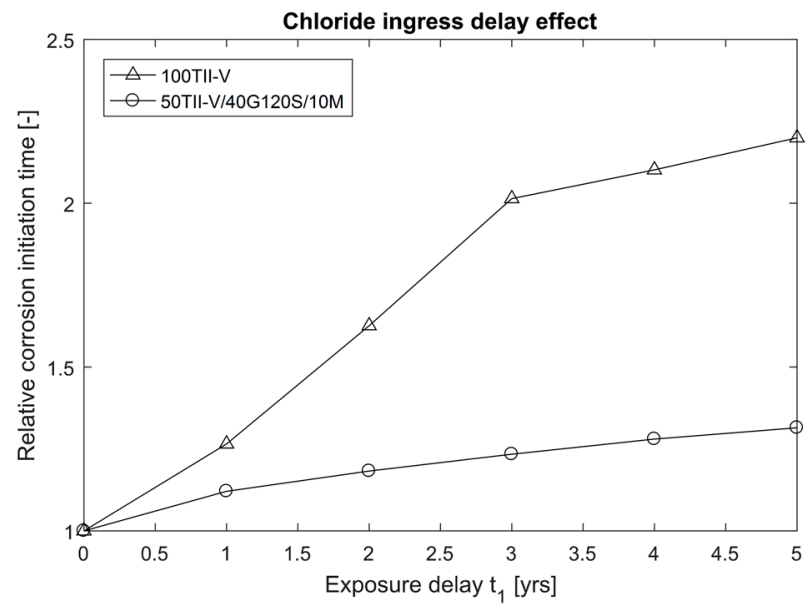

Fig. 3 The effect of delayed exposure of chlorides on relative increase of corrosion initiation time in case of ideal bridge deck without cracks for two selected concrete mixtures (ordinary concrete mix 100TII-V and high performance concrete mixture 50TII-V/40G120S/10M) [18]

\section{Parametric study}

The evaluation of the effect of concrete constitution as well as prescription of the chloride loading is addressed in considered parametric study.

\subsection{Evaluated scenarios}

Six mixtures from the study conducted in California [16] that contained 33 binary and ternary concrete mixtures are considered. The list of components of cementitious materials is given in Table 1 .

The considered alternatives for the model of chloride deicing application are given in Table 3. The models are based on the alternatives shown on the Fig. 1. The model features are: (A) constant from the age $t=0$, (B) constant from the age $t_{1}=(0 \ldots 5)$ [yrs], (C) zero at the age $t_{1}=0$, constant from the age $t_{2}=(0 \ldots 10)$ [yrs], and interpolated in between, (D) zero until the age $t_{1}=(0 \ldots 5)$, constant from the age $t_{2}=t_{1}+10[\mathrm{yrs}]$ and interpolated in between.

Table 1 Material constituents

\begin{tabular}{lc}
\hline Notation & Cementitious material description \\
\hline TII-V & Type II-V ordinary Portland cement \\
G120S & Ground granulated blast furnace slag of grade 120 \\
C & Class C fly ash \\
F & Class F fly ash \\
SF & Silica fume \\
\hline
\end{tabular}

The list of selected mixtures as well as diffusion coefficients and aging factor prepared in [19] is given in Table 2.

Table 2 Mix design model parameters

\begin{tabular}{lcc}
\hline Notation & $\begin{array}{c}\text { Diffusion coefficient } \\
D_{\mathrm{c}, 28}\left[10^{-12} \mathrm{~ms}^{-2}\right]\end{array}$ & Aging factor $m[-]$ \\
\hline 100TII-V & $5.58522 \mathrm{E}-12$ & 0.284 \\
65TII-V/35G120S & $7.91958 \mathrm{E}-12$ & 0.15247 \\
65TII-V/5SF/30C & $5.69306 \mathrm{E}-12$ & 0.52011 \\
50TII-V/40G120S/10M & $2.11108 \mathrm{E}-12$ & 0.57289 \\
75TII-V/20F/5SF & $3.27544 \mathrm{E}-12$ & 0.59725 \\
57TII-V/35G120S/7M & $3.4024 \mathrm{E}-12$ & 0.46439 \\
\hline
\end{tabular}

Table 3 Chloride concentration over the time - modelled situations

\begin{tabular}{lccc}
\hline Chloride surface concentration & Notation & $t_{1}[\mathrm{yrs}]$ & $t_{2}[\mathrm{yrs}]$ \\
\hline Constant value & FA & 0 & 0 \\
Delay and step to constant value & FA-B & $(0 \ldots 5)$ & $t_{1}$ \\
Linear build-up to constant value & FA-C & 0 & $(0 \ldots 10)$ \\
$\begin{array}{l}\text { Delay and linear build-up for 10 } \\
\text { years to reach the constant value }\end{array}$ & FA-D & $(0 \ldots 5)$ & $t_{1}+10$
\end{tabular}


The aging effect is based on the model given in Eq. (1) with the reference diffusion coefficient obtained for the age of 28 days as well as aging parameter obtained [17]. If no aging is considered than the $m$ factor in the Eq. (1) is considered equal to 1 .

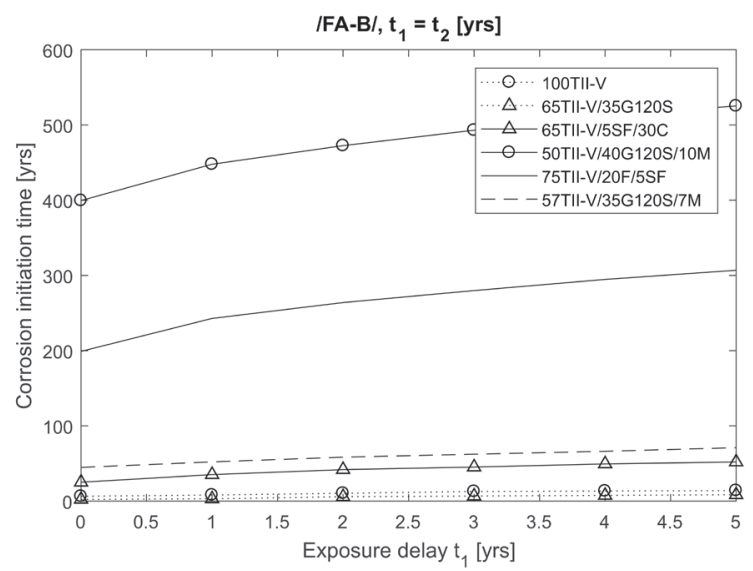

(a) Delay and step to constant value

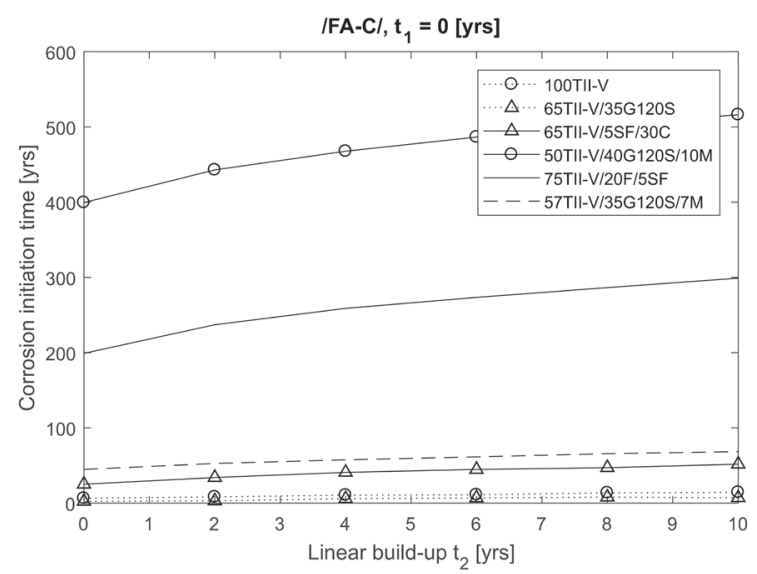

(b) Linear build-up to constant value

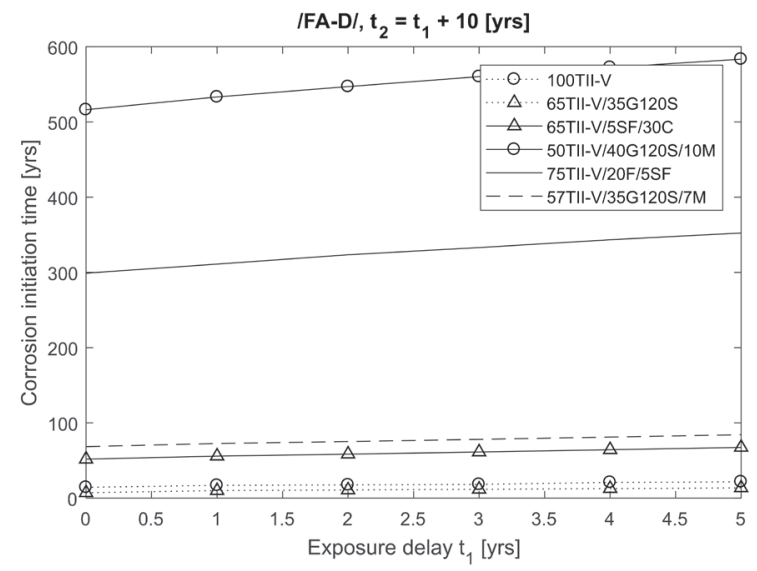

(c) Delay and linear build-up for 10 years to reach the constant value

Fig. 4 Comparison of corrosion initiation time for diffusion coefficient depending on the onset of surface chloride concentration

\subsection{Results}

The resulting time to modelled onset of corrosion of embedded conventional steel if the concrete would be ideal without influence of any cracks and if the chloride diffusion is computed based on theoretical value obtained from the laboratory tests using electrical conductivity or resistivity is given in Figs. 4 and 5.

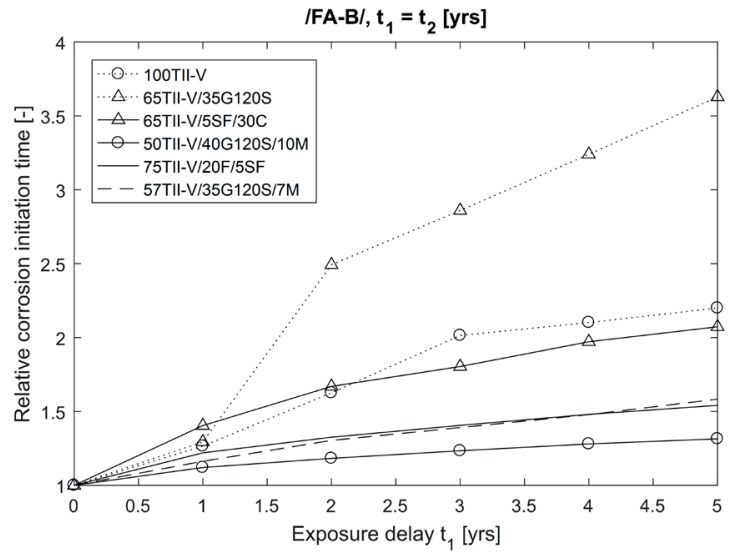

(a) Delay and step to constant value

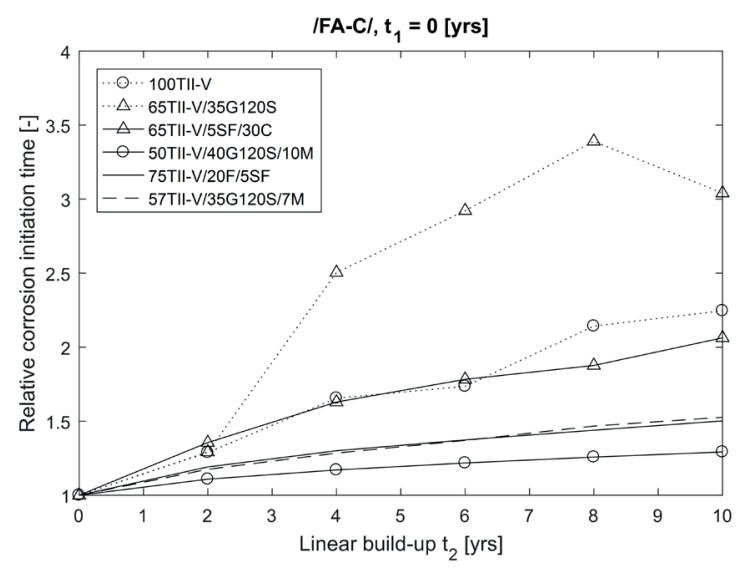

(b) Linear build-up to constant value

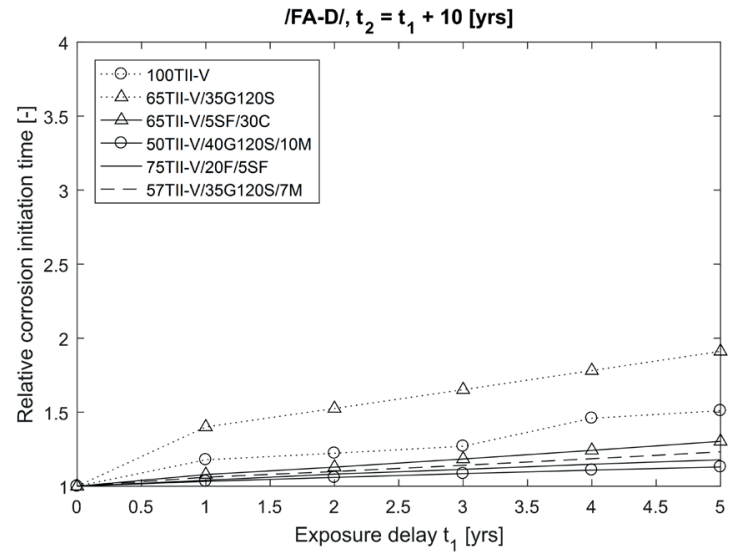

(c) Delay and linear build-up for 10 years to reach the constant value Fig. 5 Comparison of relative corrosion initiation time for diffusion coefficient depending on the onset of surface chloride concentration 
Marking the results corresponds to the information in Table 3. All graphs contain the results of the reference analysis with constant chloride concentration over the time marked as FA example. These values of the theoretical time to corrosion initiation are on the vertical axis (left side of the graph). Next, each graph corresponds to values for FA-B (Delay and Stepped increase to the chloride concentration of FA), FA-C (Linear build-up to constant value) of FA and FA-D (Delay and linear build-up for 10 years to reach the constant value of FA).

The vertical axis always represents the specific model of the delayed exposure (FA-B and FA-C) or the difference between delay and full exposure (FA-D). Fig. 4 shows the absolute values of corrosion initiation time while the Fig. 5 shows the relative values. The discussion of the results of the numerical simulation with respect to the type of mixture in relation to the diffusion coefficient value and the coefficient aging is given bellow the figures.

Looking at Fig. 4 it is clear that the best improvement was the FA-D variant where the delay in application is followed by the linear build-up of chlorides. This was the expected result. However, the comparison of absolute results of the individual concrete mixes has lower explanatory power comparing to relative one. Relative comparisons for selected mixtures are available on the Fig 5. Figure shows the ratio between the corrosion initiation time for each of the mixtures at a time given at horizontal axis divided by a result for a time parameter equating to zero.

The relative values shown clearly that for all studied cases there are linear improvement in connection with exposure delay. The only exception for F-B and F-C is the 65TIIV/35G120S, which shows a larger increase. This mixture has a high reference diffusion coefficient and a very low aging coefficient. This is representing the low-quality concrete. On the other hand, the 50TII-V/40G120S/10M, which has a low reference diffusion coefficient and a high aging factor, shows a large increase in terms of absolute values

\section{References}

[1] Stewart, M. G., Rosowsky, D. V. "Time-dependent reliability of deteriorating reinforced concrete bridge decks", Structural Safety, 20(1), pp. 91-109, 1998

https://doi.org/10.1016/S0167-4730(97)00021-0

[2] Bentz, E. C., Thomas, M. D. A. "Life-365 Service Life Prediction Model $^{\mathrm{MT}}$ and Computer Program for Predicting the Service Life and Life-Cycle Cost of Reinforced Concrete Exposed to Chlorides, Life-365 User Manual", NRMCA Engineering, Silver Spring, MD, USA, 2013. [online] Available at: https://www.nrmca.org/research/ Life365v2UsersManual.pdf [Accessed: 13 June 2019]
(Fig. 4), but in relative numbers the improvement is negligible. The results of the F-D description (delay with linear build-up of chloride concentration) yielded similar behavior for most mixtures, regardless of the starting year of salting.

\section{Summary and conclusions}

The improvement of the model of reinforced concrete bridge deck corrosion initiation assessment is discussed. The delayed chloride surface concentration boundary condition is introduced, and results of sample simulation are discussed.

The model of ideal bridge deck without crack and the aging effect on the improvement of diffusion coefficient related to concrete time dependent maturing is considered. The variants with immediate exposure are compared with delayed exposure up to 5 years. Such model may represent the delay in the application of chloride - deicers. The full application of chlorides after delay is considered herein. Five concrete mixtures are compared.

Such situation when the concrete is not exposed to chlorides in the year of construction may occur when the bridge is built, and the connecting road is not used due to technical complications with other part of the road construction or intentionally as part of the construction plan in order to improve durability.

The HPC concrete show significantly higher time to onset of corrosion comparing to ordinary concrete but the relative increase in durability was not as significant as in case of ordinary concrete mix. Moreover, the most significant effect of delayed chloride application showed concrete with highest diffusion coefficient and the lowest aging factor.

\section{Acknowledgement}

Financial support from VŠB-Technical University of Ostrava by means of the Czech Ministry of Education, Youth and Sports through the Institutional support for conceptual development of science, research and innovations for the year 2018 is gratefully acknowledged.

[3] Konecny, P., Lehner, P. "Effect of cracking and randomness of inputs on corrosion initiation of reinforced concrete bridge decks exposed to chlorides", Frattura ed Integrita Strutturale, 11(39), pp. 29-37, 2017.

https://doi.org/10.3221/IGF-ESIS.39.04

[4] Vořechovská, D., Teplý, B., Šomodíková, M. "Chloride Ion Ingress Modelling and the Reliability of Concrete Structures", In: Proceedings of the $12^{\text {th }}$ International Conference on Structural Safety and Reliability (ICOSSAR 2017), Vienna, Austria, 2017, pp. 2169 2178. [online] Available at: https://owncloud.tuwien.ac.at/index. php/s/DnQ2sWRcnhT8Zfq\#pdfviewer [Accessed: 13 June 2019] 
[5] Tikalsky, P. J., Pustka, D., Marek, P. "Statistical Variations in Chloride Diffusion in Concrete Bridges", ACI Structural Journal, 102(3), pp. 481-486, 2005.

https://doi.org/10.14359/14420

[6] Konečný, P., Tikalsky, P. J., Tepke, D. G. "Performance Evaluation of Concrete Bridge Deck Affected by Chloride Ingress: SimulationBased Reliability Assessment and Finite Element Modeling", Transportation Research Record: Journal of the Transportation Research Board, 2028(1), pp. 3-8, 2008.

https://doi.org/10.3141/2028-01

[7] Marsavina, L., Audenaert, K., De Schutter, G., Faur, N., Marsavina, D. "Experimental and numerical determination of the chloride penetration in cracked concrete", Construction and Building Materials, 23(1), pp. 264-274, 2009.

https://doi.org/10.1016/j.conbuildmat.2007.12.015

[8] Konečný, P., Brožovský, J., Ghosh, P. "Evaluation of Chloride Influence on the Cracking in Reinforced Concrete using Korozeeneck Software", Transactions of VSB - Technical University of Ostrava, Civil Engineering Series, 11(1), 2011. https://doi.org/10.2478/v10160-011-0006-y

[9] Teplý, B., Vořechovská, D. "Reinforcement Corrosion: Limit States, Reliability and Modelling", Journal of Advanced Concrete Technology, 10(11), pp. 353-362, 2012. https://doi.org/10.3151/jact.10.353

[10] Bentz, D. P., Garboczi, E. J., Lu, Y., Martys, N., Sakulich, A. R., Weiss, W. J. "Modeling of the influence of transverse cracking on chloride penetration into concrete", Cement and Concrete Composites, 38, pp. 65-74, 2013. https://doi.org/10.1016/J.CEMCONCOMP.2013.03.003

[11] Lehner, P., Konečný, P., Ghosh, P., Tran, Q. "Numerical analysis of chloride diffusion considering time-dependent diffusion coefficient", International Journal of Mathematics and Computers in Simulation, 8(1), pp. 103-106, 2014. [online] Available at: http://www.naun.org/main/NAUN/mcs/2014/a122001-315.pdf [Accessed: 13 June 2019]

[12] Special Activity Group 5 "Model Code 2010 - Final draft, Volume 1", fib bulletin No. 65, Lausanne, Switzerland, 2012. [online] Available at: https://www.fib-international.org/publications/fib-bulletins/model-code-2010-final-draft,-volume-1-142-detail.html [Accessed: 13 June 2019]

[13] Special Activity Group 5 "Model Code 2010 - Final draft, Volume 2", fib bulletin No. 66, Lausanne, Switzerland, 2012. [online] Available at: https://www.fib-international.org/publications/fib-bulletins/model-code-2010-final-draft,-volume-2-143-detail.html [Accessed: 13 June 2019]

[14] Mangat, P. S., Molloy, B. T. "Prediction of long term chloride concentration in concrete", Materials and Structures, 27(6), pp. 338346, 1994.

https://doi.org/10.1007/BF02473426

[15] Thomas, M. D. A., Phil, B., Bamforth, P. B. "Modelling chloride diffusion in concrete: Effect of fly ash and slag", Cement and Concrete Research, 29(4), pp. 487-495, 1999. https://doi.org/10.1016/S0008-8846(98)00192-6
[16] Ghosh, P., Tran, Q. "Correlation Between Bulk and Surface Resistivity of Concrete", International Journal of Concrete Structures and Materials, 9(1), pp. 119-132, 2015. https://doi.org/10.1007/s40069-014-0094-z

[17] AASHTO-T259 "Standard Method of Test for Resistance of Concrete to Chloride Ion Penetration", American Association of State Highway and Transportation Officials, Washington, DC, USA, 2012. [online] Available at: https://store.transportation.org/ item/publicationdetail/806 [Accessed: 13 June 2019]

[18] Lu, X. "Application of the Nernst-Einstein equation to concrete", Cement and Concrete Research, 27(2), pp. 293-302, 1997. https://doi.org/10.1016/S0008-8846(96)00200-1

[19] Tran, Q., Ghosh, P., Konečný, P., Lehner, P. "Determination of Time Dependent Diffusion Coefficient Aging Factor of HPC Mixtures", Key Engineering Materials, (2018, Accepted).

[20] Konečný, P., Lehner, P., Pustka, D. "Reinforced Concrete Bridge Deck Model Considering Delayed Exposure to Chlorides", In: Proceedings of the scientific conference Modelling in Mechanics 2017, Ostrava, Czech Republic, 2017, pp. 21-22.

[21] Gulikers J. J. W., Groeneweg, T. W. "Residual Service Life of Existing Concrete Structures - Is it Useful in Practice?", In: Hordijk, D. A., Luković, M. (eds.) High Tech Concrete: Where Technology and Engineering Meet, Springer, Cham, Switzerland, 2018, pp. $1840-1848$.

[22] Matthews, S. "Structural Concrete Textbook on behaviour, design and performance, Second edition, Volume 5", fib Bulletin No. 62, Lausanne, Switzerland, 2012. [online] Available at: https://www. fib-international.org/publications/fib-bulletins/structural-concrete-textbook,-volume-5-detail.html [Accessed: 13 June 2019]

[23] Yan, Y., Ling, W., Wittmann, F. H. "Publications on Durability of Reinforced Concrete Structures under Combined Mechanical Loads and Environmental Actions: An Annotated Bibliography", Aedificatio Publishers, Freiburg im Breisgau, Germany, 2013. https://doi.org/10.12900/B14-0001

[24] Zhang, X., Zhao, Y., Xing, F., Lu, Z. "Coupling effects of influence factors on probability of corrosion initiation time of reinforced concrete", Journal of Central South University of Technology, 18(1), pp. 223-229. 2011. https://doi.org/10.1007/s11771-011-0683-9

[25] Kubzova, M., Krivy, V., Kreislova, K. "Influence of Chloride Deposition on Corrosion Products", Procedia Engineering, 192, pp. 504-509, 2017. https://doi.org/10.1016/j.proeng.2017.06.087

[26] Krivy, V., Kubzova, M., Kreislova, K., Urban, V. "Characterization of Corrosion Products on Weathering Steel Bridges Influenced by Chloride Deposition", Metals, 7(9), 2017. https://doi.org/10.3390/met7090336

[27] Ghosh, P., Konečný, P., Tikalsky, P. J. "SBRA Model for Corrosion Initiation of Concrete Structures", In: Andrade, C., Mancini, G. (eds.) Modelling of Corroding Concrete Structures, 1st ed., Springer, Dordrecht, Netherlands, 2011, pp. 85-100. https://doi.org/10.1007/978-94-007-0677-4_5 